\title{
Insights Into Highly Improved Solar-Driven Photocatalytic Oxygen Evolution Over Integrated $\mathrm{Ag}_{3} \mathrm{PO}_{4} / \mathrm{MoS}_{2}$ Heterostructures
}

\section{OPEN ACCESS}

Edited by:

Fan Dong,

Chongaing Technology and Business

University, China

Reviewed by:

Kangle $L v$,

South-Central University for

Nationalities, China

Yanhui Ao,

Hohai University, China

Shichao Tian,

Research Institute of Tsinghua

University in Shenzhen, China

*Correspondence:

Xiaofei Yang

xiaofei_yang1980@163.com;

xiaofei.yang@nifu.edu.cn

Qinqin Liu

liu_qin_qin@126.com

Specialty section

This article was submitted to Catalysis and Photocatalysis,

a section of the journal

Frontiers in Chemistry

Received: 13 March 2018

Accepted: 03 April 2018

Published: 18 April 2018

Citation:

Cui X, Yang X, Xian X, Tian L, Tang H and Liu Q (2018) Insights Into Highly Improved Solar-Driven Photocatalytic

Oxygen Evolution Over Integrated

$\mathrm{Ag}_{3} \mathrm{PO}_{4} / \mathrm{MoS}_{2}$ Heterostructures

Front. Chem. 6:123.

doi: 10.3389/fchem.2018.00123

\author{
Xingkai Cui ${ }^{1}$, Xiaofei Yang ${ }^{1,2,3 *}$, Xiaozhai Xian ${ }^{1}$, Lin Tian ${ }^{1}$, Hua Tang ${ }^{1}$ and Qinqin Liu ${ }^{1 *}$
}

${ }^{1}$ School of Materials Science and Engineering, Jiangsu University, Zhenjiang, China, ${ }^{2}$ College of Science, Nanjing Forestry University, Nanjing, China, ${ }^{3}$ State Key Laboratory of Photocatalysis on Energy and Environment, Fuzhou University, Fuzhou, China

Oxygen evolution has been considered as the rate-determining step in photocatalytic water splitting due to its sluggish four-electron half-reaction rate, the development of oxygen-evolving photocatalysts with well-defined morphologies and superior interfacial contact is highly important for achieving high-performance solar water splitting. Herein, we report the fabrication of $\mathrm{Ag}_{3} \mathrm{PO}_{4} / \mathrm{MoS}_{2}$ nanocomposites and, for the first time, their use in photocatalytic water splitting into oxygen under LED light illumination. $\mathrm{Ag}_{3} \mathrm{PO}_{4}$ nanoparticles were found to be anchored evenly on the surface of $\mathrm{MoS}_{2}$ nanosheets, confirming an efficient hybridization of two semiconductor materials. A maximum oxygen-generating rate of $201.6 \mu \mathrm{mol} \cdot \mathrm{L}^{-1} \cdot \mathrm{g}^{-1} \cdot \mathrm{h}^{-1}$ was determined when $200 \mathrm{mg} \mathrm{MoS} 2$ nanosheets were incorporated into $\mathrm{Ag}_{3} \mathrm{PO}_{4}$ nanoparticles, which is around 5 times higher than that of bulk $\mathrm{Ag}_{3} \mathrm{PO}_{4}$. Obvious enhancements in light-harvesting property, as well as electron-hole separation and charge transportation are revealed by the combination of different characterizations. ESR analysis verified that more active oxygen-containing radicals generate over illuminated $\mathrm{Ag}_{3} \mathrm{PO}_{4} / \mathrm{MoS}_{2}$ composite photocatalysts rather than irradiated $\mathrm{Ag}_{3} \mathrm{PO}_{4}$. The improvement in oxygen evolution performance of $\mathrm{Ag}_{3} \mathrm{PO}_{4} / \mathrm{MoS}_{2}$ composite photocatalysts is ascribed to wide spectra response in the visible-light region, more efficient charge separation, and enhanced oxidation capacity in the valence band (VB). This study provides new insights into the design and development of novel composite photocatalytic materials for solar-to-fuel conversion.

Keywords: $\mathrm{Ag}_{3} \mathrm{PO}_{4}, \mathrm{MoS}_{2}$, composite photocatalyst, oxygen evolution, water splitting, Z-scheme

\section{INTRODUCTION}

Inspired by natural photosynthesis, the construction of visible-light-responsive functional semiconducting materials for highly efficient photocatalytic water splitting and reduction of $\mathrm{CO}_{2}$ has drawn considerable attention over the past few years (Maeda and Domen, 2010; Mikkelsen et al., 2010; Takanabe, 2017; Zheng et al., 2017). Especially, water splitting into hydrogen and oxygen has been intensively investigated due to the nature of clean and sustainable solar-to-fuel conversion. Compared with the hydrogen evolution reaction (HER), four-electron water oxidation process is more difficult to be fulfilled since a higher potential more than $1.23 \mathrm{eV}$ is required 
(Kudo and Miseki, 2009), mostly an overpotential is also required. Thus, oxygen evolution is considered as the ratedetermining step in photocatalytic overall water splitting process. So far only few semiconductors such as $\mathrm{WO}_{3}, \mathrm{BiVO}_{4}$, have been employed as photocatalysts for oxygen production from water splitting (Xin et al., 2009; Wu et al., 2016; Zeng et al., 2017; He et al., 2018). Due to the limitations of band structures and light-harvesting properties in the visible light region, the utilization of sing-component semiconductors as catalysts for oxygen evolution has encountered serious difficulties, the design and development of novel composite materials for solar-driven photocatalytic water splitting are highly desirable.

Since the pioneer work of silver phosphate $\left(\mathrm{Ag}_{3} \mathrm{PO}_{4}\right)$ semiconductor for photocatalytic applications in 2010 (Yi et al., 2010). Many efforts have been devoted to synthesize $\mathrm{Ag}_{3} \mathrm{PO}_{4}$ photocatalysts with different nanostructures and a variety of $\mathrm{Ag}_{3} \mathrm{PO}_{4}$-based composite photocatalytic materials for energy and environmental applications (Bi et al., 2012; Wang et al., 2012; Hu et al., 2013; Cao et al., 2017). Nanostructure engineering of pristine $\mathrm{Ag}_{3} \mathrm{PO}_{4}$ and hybridization of $\mathrm{Ag}_{3} \mathrm{PO}_{4}$ with other semiconductors have been proven to offer superior advantages in light absorption, electronhole separation and charge transportation, resulting in the enhancement in the photocatalytic activity (Yang et al., 2015b; Lv et al., 2016; Wang et al., 2017; Zhou et al., 2018). The key to synthesizing highly efficient $\mathrm{Ag}_{3} \mathrm{PO}_{4}$-based composite photocatalysts lies in screening promising candidates with matched band structures and constructing heterojunctions with optimal morphologies and interfaces, where favorable visible light utilization and tandem charge transfer pathway should be taken into consideration. The past decades have witnessed the use of molybdenum disulfide $\left(\mathrm{MoS}_{2}\right)$, a 2D lamellar material with excellent conductive property, as electrocatalysts and photocatalysts for applications in electrochemical and solar-tofuel conversion (Xiang et al., 2012; Dai et al., 2017; Yang et al., 2017). It was confirmed that the combination of $\mathrm{MoS}_{2}$ with functional semiconductors enabled obvious enhancements in both photocatalytic and electrocatalytic hydrogen production activity (Sun et al., 2016; Zhang et al., 2016; Iqbal et al., 2017; Yuan et al., 2017). The hybridization of $\mathrm{MoS}_{2}$ with $\mathrm{Ag}_{3} \mathrm{PO}_{4}$ to produce $\mathrm{MoS}_{2} / \mathrm{Ag}_{3} \mathrm{PO}_{4}$ composite materials has been primarily explored, however the application is restricted to the photodegradation of different kinds of organic pollutants (Wang L. et al., 2015; Wang P. F. et al., 2015; Gyawali and Lee, 2016; Li et al., 2016; Zhu et al., 2016; Wan et al., 2017), the employment of $\mathrm{MoS}_{2} / \mathrm{Ag}_{3} \mathrm{PO}_{4}$ nanocomposites as photocatalysts for solar-lightdriven oxygen evolution from water splitting has not yet been explored.

Most recently, we reported the in-situ deposition of $\mathrm{Ag}_{3} \mathrm{PO}_{4}$ on graphitic carbon nitride $\left(\mathrm{g}-\mathrm{C}_{3} \mathrm{~N}_{4}\right)$ nanostructures for highly efficient Z-scheme oxygen evolution from water splitting (Yang et al., 2015a,c; Cui et al., 2018; Tian et al., 2018). In consideration of the matched band structures of bulk $\mathrm{Ag}_{3} \mathrm{PO}_{4}$ and $\mathrm{MoS}_{2}$ materials for redox reactions, in this work, we demonstrate the hybridization of oxygen-producing photocatalyst $\mathrm{Ag}_{3} \mathrm{PO}_{4}$ with few-layered, two-dimensional $\mathrm{MoS}_{2}$ nanosheets, and the use of $\mathrm{Ag}_{3} \mathrm{PO}_{4} / \mathrm{MoS}_{2}$ nanocomposites for photocatalytic water oxidation under LED illumination. Asprepared hybrid materials exhibit well-organized nanostructures, in which sheet-like $\mathrm{MoS}_{2}$ materials provide sufficient active sites for the deposition of $\mathrm{Ag}_{3} \mathrm{PO}_{4}$ nanoparticles. It is for the first time that oxygen evolution performance over the obtained $\mathrm{Ag}_{3} \mathrm{PO}_{4} / \mathrm{MoS}_{2}$ composite photocatalysts has been evaluated, moreover, the effects of highly conductive $\mathrm{MoS}_{2}$ materials on visible light utilization, electron-hole separation and water oxidation efficiency are systematically revealed.

\section{EXPERIMENTAL}

\section{Preparation}

$\mathrm{MoS}_{2}$ nanosheets were fabricated by the ultrasonic stripping of commercially available $\mathrm{MoS}_{2}$ materials. In a typical synthesis of $\mathrm{Ag}_{3} \mathrm{PO}_{4} / \mathrm{MoS}_{2}$ nanocomposites, different amounts of sheetlike $\mathrm{MoS}_{2}(50,100,200,300 \mathrm{mg})$ were added into $90 \mathrm{~mL} \mathrm{H} \mathrm{H}_{2} \mathrm{O}$, respectively, followed by the ultrasonic treatment for $3 \mathrm{~h}$. Next, $30 \mathrm{~mL}$ of $\mathrm{AgNO}_{3}$ (18 mmol, $3.06 \mathrm{~g}$ ) aqueous solution was added dropwise into the $\mathrm{MoS}_{2}$ suspension, and stirred for further $12 \mathrm{~h}$. And then $30 \mathrm{~mL}$ of $\mathrm{Na}_{3} \mathrm{PO}_{4}(6 \mathrm{mmol}, 2.28 \mathrm{~g})$ aqueous solution was added slowly into the above mixture, followed by continuous stirring for $3 \mathrm{~h}$. After high-speed centrifugation, solid products were washed with deionized water and ethanol repeatedly, and dried at $60^{\circ} \mathrm{C}$ for $12 \mathrm{~h}$. The final products were collected and are denoted as AM-50, AM-100, AM-200, and AM-300.

\section{Characterizations}

X-ray diffraction (XRD) was measured using $\mathrm{Cu} \quad \mathrm{K} \alpha$ radiation with the $2 \theta$ range from 5 to $80^{\circ}$ at a scan rate of $5^{\circ} \mathrm{min}^{-1}$ on D/MAX2500PC. Raman spectra were recorded by Thermo Scientific ${ }^{\mathrm{TM}}$ DXR spectrometer operating at $532 \mathrm{~nm}$. X-ray photoelectron spectroscopy (XPS) was evaluated by Perkin-Elmer PHI 5000C. The field-emission scanning electron microscopy (FE-SEM) was performed on JSM-7001F. The Ultraviolet-visible diffuse reflectance spectrophotometer (UV-vis DRS) on UV2450 from 200 to $800 \mathrm{~nm}$ with $\mathrm{BaSO}_{4}$ as reference standard. Photoluminescence (PL) emission measurements were carried out by a QuantaMaster ${ }^{\mathrm{TM}} 40$ with an excitation wavelength of $420 \mathrm{~nm}$. The electron spin resonance (ESR) measurements were recorded on a JES FA200 Spectrometer using the 5, 5-dimethyl-1-pyrroline-N-oxide (DMPO) as the radical capture reagent.

\section{Photocatalytic Measurements}

The efficiency of photocatalytic oxygen evolution was monitored by in-situ oxygen sensor in a sealed system connected with a circulation system. Before the measurement, oxygen-free and air-saturated water were used to calibrate the oxygen probe with temperature compensation. For the measurement of oxygen evolution, $0.3 \mathrm{~g}$ of the photocatalyst powder was added into $\mathrm{AgNO}_{3}$ aqueous solution $(100 \mathrm{~mL}, 10 \mathrm{~g} / \mathrm{L})$, followed by an ultrasonic treatment for $5 \mathrm{~min}$. 

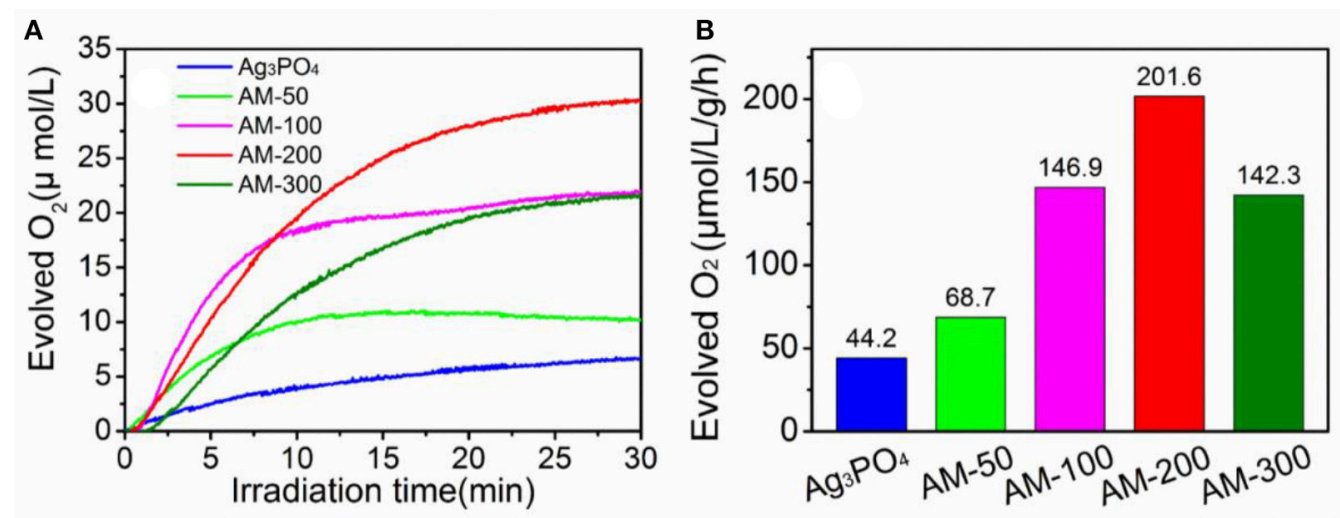

FIGURE 1 | Oxygen-evolving concentrations (A) and rates (B) over different photocatalysts under LED illumination.
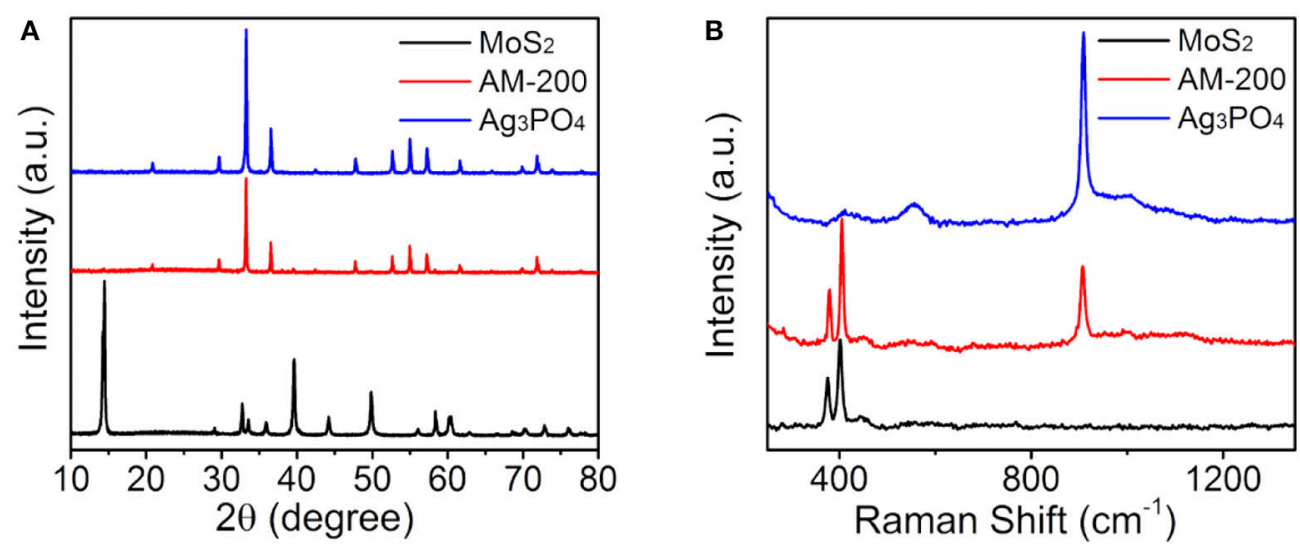

FIGURE 2 | XRD patterns (A) and Raman spectra (B) of pure $\mathrm{Ag}_{3} \mathrm{PO}_{4}, \mathrm{MoS}_{2}$, and the composite AM-200.

\section{RESULTS AND DISCUSSION}

Photocatalytic oxygen evolution from water splitting over pure $\mathrm{Ag}_{3} \mathrm{PO}_{4}$ and $\mathrm{Ag}_{3} \mathrm{PO}_{4} / \mathrm{MoS}_{2}$ composites with different mass ratios were evaluated, and the results are presented in Figure $\mathbf{1 .}$ It can be observed (Figure 1A) that the amount of evolved oxygen increases gradually when 50 and $100 \mathrm{mg} \mathrm{MoS}_{2}$ were employed, the highest concentration of produced oxygen was recorded when the content of $\mathrm{MoS}_{2}$ was increased to $200 \mathrm{mg}$. Further increase in the $\mathrm{MoS}_{2}$ content from 200 to $300 \mathrm{mg}$ in the $\mathrm{Ag}_{3} \mathrm{PO}_{4} / \mathrm{MoS}_{2}$ composite resulted in the deterioration in the oxygen-generating performance. Notably all the composites showed improved oxygen-evolving performance than bulk $\mathrm{Ag}_{3} \mathrm{PO}_{4}$ material. The oxygen-evolving rates of as-prepared samples under LED illumination are further quantified and shown in Figure 1B. When $200 \mathrm{mg} \mathrm{MoS}_{2}$ was introduced to hybridize with $\mathrm{Ag}_{3} \mathrm{PO}_{4}$, an optimal oxygen-generating rate of $201.6 \mu \mathrm{mol} \cdot \mathrm{L}^{-1} \cdot \mathrm{g}^{-1} \cdot \mathrm{h}^{-1}$ was determined, which is about 4.5 times higher than that of pure $\mathrm{Ag}_{3} \mathrm{PO}_{4}$. It can be concluded from the oxygen evolution performance that a proper addition of $\mathrm{MoS}_{2}$ may promote the water oxidation efficiency, while the use of more than $200 \mathrm{mg}$ of $\mathrm{MoS}_{2}$ is found to show negative effects on the oxygen evolution performance. For simplicity, only the composite AM-200 with the best oxygen-producing efficiency is chosen for comparisons with two starting materials in the following sections.

Following the evaluation of photocatalytic oxygen evolution performance, phase structures of the AM-200 composite were confirmed by XRD patterns (Figure 2A). Diffraction peaks (black line) appearing in $14.32,32.62,33.44,35,82,39.48,44,1,49.72$, $58.24,60.32$, and $72.72^{\circ}$ can be assigned to the (002), (100), (101), (102), (103), (006), (105), (110), (008), and (203) planes of hexagonal $\mathrm{MoS}_{2}$ (JCPDS No. 37-1492). And the characteristic peaks (blue line) located at 20.96, 29.78, 33.38, 36.66, 47.86, $52.76,55.1,57.34,61.72$, and $73.94^{\circ}$ correspond to planes (110), (200), (210), (211), (310), (222), (320), (321), (400), and (332) of bulk $\mathrm{Ag}_{3} \mathrm{PO}_{4}$ (JCPDS No. 06-0505), respectively. No obvious difference can be observed in characteristic diffraction peaks of bulk $\mathrm{Ag}_{3} \mathrm{PO}_{4}$ and $\mathrm{Ag}_{3} \mathrm{PO}_{4} / \mathrm{MoS}_{2}$ composite (AM-200), presumably due to a relatively weaker diffraction intensity of $\mathrm{MoS}_{2}$. The molecular structures of pure $\mathrm{MoS}_{2}$, bulk $\mathrm{Ag}_{3} \mathrm{PO}_{4}$ and the $\mathrm{Ag}_{3} \mathrm{PO}_{4} / \mathrm{MoS}_{2}$ composite AM-200 were further characterized 

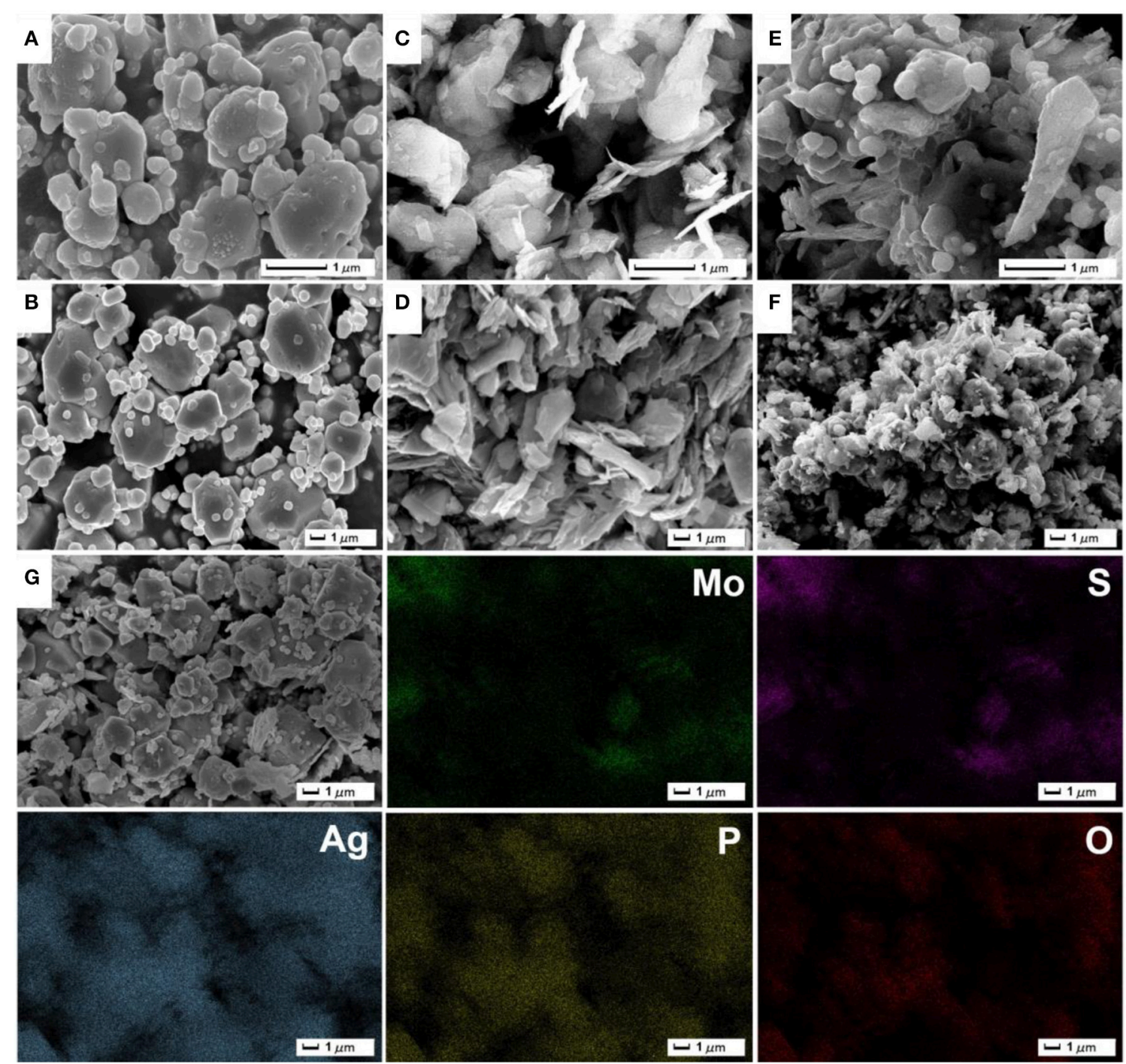

P

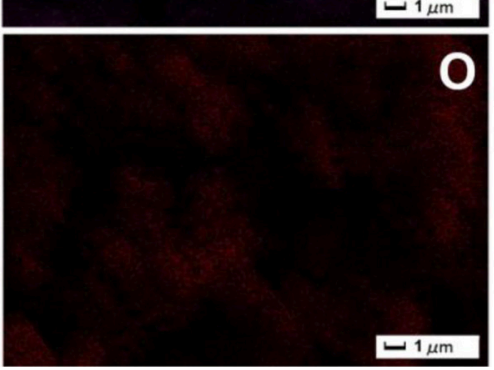

FIGURE 3 | Low-magnification (A,C,E) and high-magnification (B,D,F) SEM images of pure $\mathrm{Ag}_{3}$ PO 4 (A,B), MoS 2 (C,D) as well as the composite AM-200 (E,F); EDS element mapping images of AM-200 (G).

by Raman spectra (Figure 2B). In the spectrum of $\mathrm{Ag}_{3} \mathrm{PO}_{4}$, a sharp absorption peak at $908.5 \mathrm{~cm}^{-1}$ can be attributed to the motion of terminal oxygen bond vibration in phosphate chains. The peak at $1002.4 \mathrm{~cm}^{-1}$ is ascribed to the asymmetric stretching vibrations of $\mathrm{O}-\mathrm{P}-\mathrm{O}$ bonds in $\left[\mathrm{PO}_{4}\right]$ clusters. The broad peak located at $554.4 \mathrm{~cm}^{-1}$ arises from the asymmetric stretch of P-O-P bonds, while the peak centered at 406.1 $\mathrm{cm}^{-1}$ corresponds to the symmetric bending vibration modes related to $\left[\mathrm{PO}_{4}\right]$ clusters (Botelho et al., 2015). For pure $\mathrm{MoS}_{2}$, characteristic Raman shifts located at 375.8 and 402.1 $\mathrm{cm}^{-1}$ are assigned to the $\mathrm{E}_{2 \mathrm{~g}}$ and $\mathrm{A}_{1 \mathrm{~g}}$ modes, while the peak appearing at $446.2 \mathrm{~cm}^{-1}$ is suggested to come from the interaction of the longitudinal acoustic phonon and Raman inactive $\mathrm{A}_{2 \mathrm{u}}$ modes (Koroteev et al., 2011; Lukowski et al., 2013). All characteristic peaks of both $\mathrm{Ag}_{3} \mathrm{PO}_{4}$ and $\mathrm{MoS}_{2}$ were detected in Raman spectrum of the $\mathrm{Ag}_{3} \mathrm{PO}_{4} / \mathrm{MoS}_{2}$ composite
AM-200, indicating a complete hybridization of $\mathrm{Ag}_{3} \mathrm{PO}_{4}$ with $\mathrm{MoS}_{2}$.

The morphologies of as-prepared samples were recorded by SEM images (Figure 3). From Figures $\mathbf{3} \mathbf{A}, \mathbf{B}$, as-synthesized $\mathrm{Ag}_{3} \mathrm{PO}_{4}$ products present an irregular polyhedron structure with the size of about $1-3 \mu \mathrm{m}$, and a few of small particles are distributed around large particles. SEM images of ultrasonictreated $\mathrm{MoS}_{2}$ material (Figures 3C,D) shows that stripped $\mathrm{MoS}_{2}$ exhibit a thin sheet-like nanostructure. The stripped $\mathrm{MoS}_{2}$ layer-like material has a certain accumulation and parts of $\mathrm{MoS}_{2}$ materials have not been stripped into pieces. The $\mathrm{Ag}_{3} \mathrm{PO}_{4} / \mathrm{MoS}_{2}$ composite AM-200 was synthesized by the in-situ deposition of $\mathrm{Ag}_{3} \mathrm{PO}_{4}$ nanoparticles on the surface of $\mathrm{MoS}_{2}$ nanosheets via electrostatically driven self-assembly. As displayed in Figures 3E,F, the $\mathrm{Ag}_{3} \mathrm{PO}_{4}$ particles are uniformly distributed on the $\mathrm{MoS}_{2}$ nanosheets without obvious agglomeration. It can 

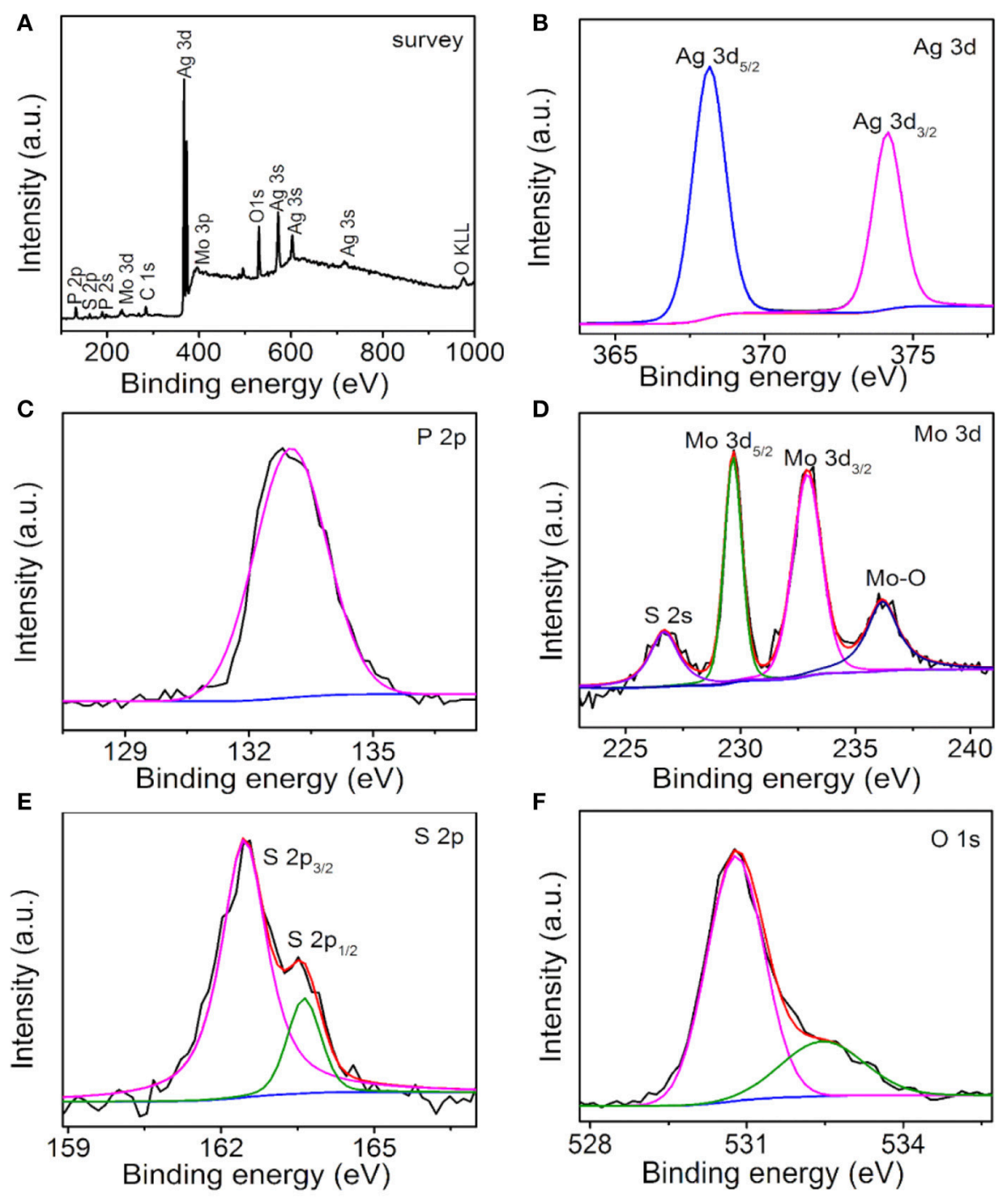

FIGURE 4 | XPS spectra of AM-200: Survey (A), Ag 3d (B), P 2p (C), Mo 3d (D), S 2p (E), and O 1s (F).
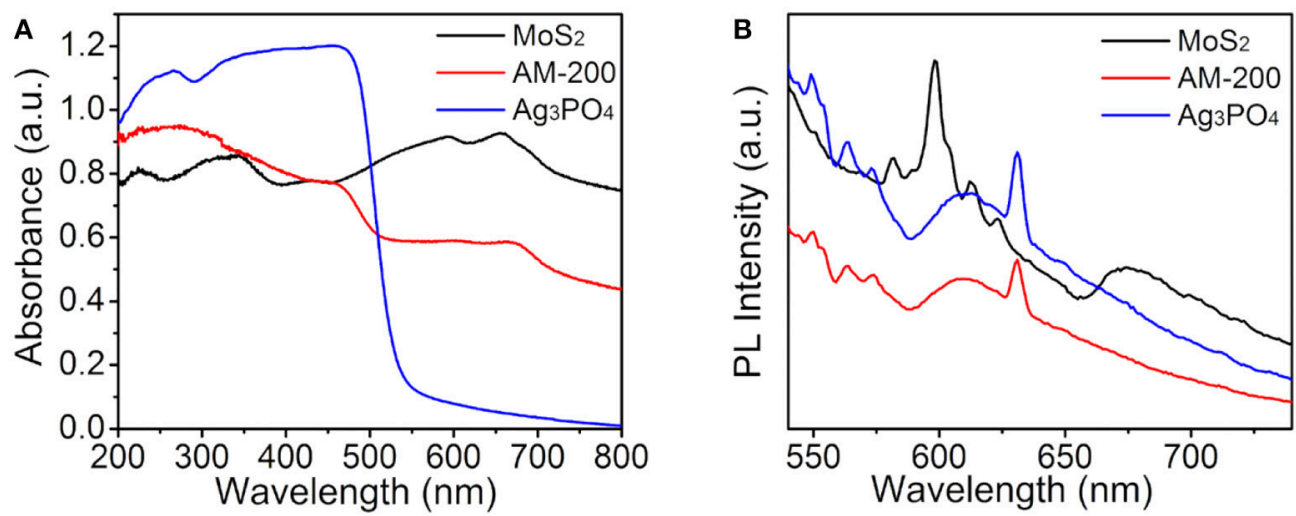

FIGURE 5 | UV-vis DRS (A) and PL spectra (B) of pure $\mathrm{Ag}_{3} \mathrm{PO}_{4}, \mathrm{MoS}_{2}$ and the composite AM-200. 

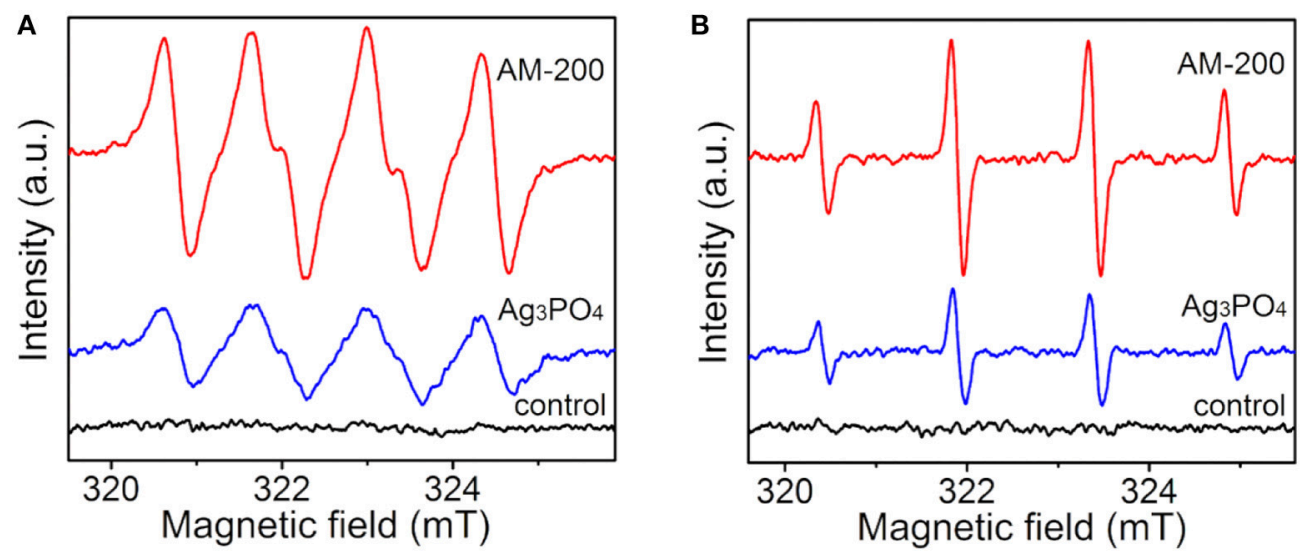

FIGURE 6 | ESR spectra of radical adducts trapped by DMPO in methanol (A) and aqueous (B) dispersions of $\mathrm{Ag}_{3} \mathrm{PO} \mathrm{O}_{4}$ and $\mathrm{AM}-200$ under light irradiation.

be observed that the particle size of $\mathrm{Ag}_{3} \mathrm{PO}_{4}$ in $\mathrm{AM}-200$ decreases slightly and is more uniform when a certain amount of $\mathrm{MoS}_{2}$ were hybridized with $\mathrm{Ag}_{3} \mathrm{PO}_{4}$, suggesting that the addition of $\mathrm{MoS}_{2}$ nanosheets have an effect on the particle size of $\mathrm{Ag}_{3} \mathrm{PO}_{4}$. The EDS element mapping images of AM-200 suggest that Mo, S, Ag, P, and O elements are homogeneously distributed, confirming the complete hybridization of $\mathrm{Ag}_{3} \mathrm{PO}_{4}$ particles and $\mathrm{MoS}_{2}$ nanosheets.

The surface chemical compositions and states of the $\mathrm{Ag}_{3} \mathrm{PO}_{4} / \mathrm{MoS}_{2}$ composite AM-200 were investigated by XPS characterization, the results are shown in Figure 4. Ag, P, O, Mo, S, and $\mathrm{C}$ elements can be detected in the survey spectrum (Figure 4A) of as-prepared composite AM-200. The existence of $C 1$ s peak is may due to the adventitious carbon on the surface of sample. In the high resolution spectrum of $\mathrm{Ag} 3 \mathrm{~d}$ (Figure 4B), two peaks at 368.1 and $374.2 \mathrm{eV}$ can be assigned to the $\mathrm{Ag} 3 \mathrm{~d}_{5 / 2}$ and $\mathrm{Ag} 3 \mathrm{~d}_{3 / 2}$, respectively. The broad peak in the P 2p spectrum (Figure 4C) located at $133.0 \mathrm{eV}$ originates from the $\mathrm{P}^{5+}$ in the $\mathrm{Ag}_{3} \mathrm{PO}_{4}$. The high resolution spectrum of Mo $3 \mathrm{~d}$ is displayed in Figure 4D, the peaks at 226.7, 229.7, 232.9, and $236.2 \mathrm{eV}$ can be ascribed to the $\mathrm{S} 2 \mathrm{~s}$, Mo $3 \mathrm{~d}_{5 / 2}$, Mo $3 \mathrm{~d}_{3 / 2}$, and Mo-O binding, respectively. Particularly, the first three binding energies indicated that $S$ and Mo elements in the $\mathrm{MoS}_{2}$ are found in the form of $\mathrm{S}^{2-}$ and $\mathrm{Mo}^{4+}$, respectively, and the last one might result from the exposed Mo atoms during the exfoliation process combining with the $\mathrm{O}$ of $\mathrm{Ag}_{3} \mathrm{PO}_{4}$ (Wan et al., 2017). The S 2p XPS spectrum (Figure 4E) can be divided into two peaks centered at 162.5 and $163.6 \mathrm{eV}$, respectively, corresponding to the $S 2 p_{3 / 2}$ and $S 2 p_{1 / 2}$ in the $M_{0}$. The spectrum of $\mathrm{O}$ 1s (Figure 4F) can be fitted into two peaks located at 530.8 and $532.5 \mathrm{eV}$, originating from the $\mathrm{O}^{2-}$ in the $\mathrm{Ag}_{3} \mathrm{PO}_{4}$ and the hydroxyl group, respectively.

It is well-known that the utilization of visible light is one of key factors affecting the activity of a photocatalyst, therefore, the light-harvesting properties of all samples were measured by UVvis DRS ranging from 200 to $800 \mathrm{~nm}$ and the absorption spectra are presented in Figure 5A. It can be seen that pure $\mathrm{Ag}_{3} \mathrm{PO}_{4}$ has a clear absorption edge around $530 \mathrm{~nm}$, and black $\mathrm{MoS}_{2}$ material reveals full-spectrum absorption in the range of $200-800 \mathrm{~nm}$. The light absorption intensity of $\mathrm{Ag}_{3} \mathrm{PO}_{4} / \mathrm{MoS}_{2}$ composite AM200 in the wavelength range of $500-800 \mathrm{~nm}$ was increased when a certain amount of $\mathrm{MoS}_{2}(200 \mathrm{mg})$ were employed to hybridize with $\mathrm{Ag}_{3} \mathrm{PO}_{4}$, implying that the integration of $\mathrm{MoS}_{2}$ with $\mathrm{Ag}_{3} \mathrm{PO}_{4}$ favors a more efficient utilization of visible light. In addition to the light absorption, the separation of photoinduced electron-hole pairs is also believed to play a predominant role in determining the photocatalytic activity, thus the recombination of photogenerated charge carrier for the as-synthesized samples was analyzed by PL spectroscopy measurements. Figure 5B reveals $\mathrm{Ag}_{3} \mathrm{PO}_{4}$ has a strong excitation peak around $630 \mathrm{~nm}$, stemming from the recombination of electrons and holes. After the addition of $\mathrm{MoS}_{2}$, the $\mathrm{Ag}_{3} \mathrm{PO}_{4} / \mathrm{MoS}_{2}$ composite AM-200 presented a similar position of excitation peak with $\mathrm{Ag}_{3} \mathrm{PO}_{4}$, and the PL emission intensity of AM-200 was weaker than those of pure $\mathrm{MoS}_{2}$ and $\mathrm{Ag}_{3} \mathrm{PO}_{4}$, suggesting that the recombination efficiency of photoexcited charge carriers in the $\mathrm{Ag}_{3} \mathrm{PO}_{4} / \mathrm{MoS}_{2}$ composite AM-200 has been effectively suppressed when the heterostructured composite was formed. A slower recombination rate of photogenerated electron-hole pairs boosts the enhancement in the photocatalytic performance.

To further determine the influence of the redox capacity of samples on the photocatalytic activity, as well as to investigate the mechanism behind the enhanced photocatalytic oxygen evolution from water splitting, the ESR measurement was carried out to confirm active radicals in-situ formed under light illumination. It can be observed in Figure 6A that no obvious peak was detected in dark. Under illumination, several strong peaks arising from DMPO-captured radicals can be detected in methanol dispersion for both pure $\mathrm{Ag}_{3} \mathrm{PO}_{4}$ and the $\mathrm{Ag}_{3} \mathrm{PO}_{4} / \mathrm{MoS}_{2}$ composite AM-200, typical peaks are assigned to the spin adducts (DMPO-O $\left.{ }_{2}^{\bullet-}\right)$. Compared with signals derived from pure $\mathrm{Ag}_{3} \mathrm{PO}_{4}$, higher signal intensities of DMPO-captured superoxide radicals were observed in the methanol dispersion of AM-200. It is shown in Figure 6B that no radical signal was detected in dark. A typical intensity ratio of 1:2:2:1 was determined from the spin adducts in aqueous dispersions of 
both $\mathrm{Ag}_{3} \mathrm{PO}_{4}$ and $\mathrm{AM}-200$ under light irradiation, representing the generation of the spin adducts (DMPO-•OH). Similarly, the intensity of radical signal for AM-200 increased largely comparable to that of $\mathrm{Ag}_{3} \mathrm{PO}_{4}$. On the basis of the above results, it is concluded that higher intensities of both photo-induced $\mathrm{O}_{2}^{\bullet-}$ and $\bullet \mathrm{OH}$ were recorded when a proper amount of $\mathrm{MoS}_{2}$ was employed.

Furthermore, the band edge positions of valence band (VB) and conduction band (CB) also have an important effect on the redox catalytic capability, which can be deduced by the following formula (Li et al., 2016):

$$
\begin{aligned}
& \mathrm{E}_{\mathrm{VB}}=\chi-\mathrm{E}_{\mathrm{e}}+0.5 \mathrm{E}_{\mathrm{g}} \\
& \mathrm{E}_{\mathrm{CB}}=\mathrm{E}_{\mathrm{VB}}-\mathrm{E}_{\mathrm{g}}
\end{aligned}
$$

Where $\mathrm{E}_{\mathrm{CB}}$ and $\mathrm{E}_{\mathrm{VB}}$ represent the $\mathrm{CB}$ and $\mathrm{VB}$ edge potentials, respectively; $\chi$ is the electro-negativity of the semiconductor, which is the geometric mean of the electro-negativities of the constituent atoms, and $\chi$-values for $\mathrm{Ag}_{3} \mathrm{PO}_{4}$ and $\mathrm{MoS}_{2}$ are 5.96 and $5.32 \mathrm{eV}$ (Wan et al., 2017), respectively. $\mathrm{E}_{\mathrm{e}}$ is about $4.5 \mathrm{eV}$, representing the free electron energy on the hydrogen scale. $\mathrm{E}_{\mathrm{g}}$ was the band gap energy of the semiconductor, and $\mathrm{E}_{\mathrm{g}}$ values for $\mathrm{Ag}_{3} \mathrm{PO}_{4}$ and $\mathrm{MoS}_{2}$ are about 2.45 and $1.9 \mathrm{eV}$ (Yang et al., 2015c; Li et al., 2016), respectively. According to the calculation, the $\mathrm{E}_{\mathrm{VB}}$-values of $\mathrm{Ag}_{3} \mathrm{PO}_{4}$ and $\mathrm{MoS}_{2}$ are about 2.69 and $1.77 \mathrm{eV}$, the top of which for both $\mathrm{Ag}_{3} \mathrm{PO}_{4}$ and $\mathrm{MoS}_{2}$ is more positive than the redox potential of $\mathrm{O}_{2} / \mathrm{H}_{2} \mathrm{O}(1.23 \mathrm{eV})$ (Xie et al., 2013), theoretically both two semiconductors are able to split water into oxygen. However, overpotential is generally required for practical water splitting, in this study, $\mathrm{Ag}_{3} \mathrm{PO}_{4}$ acts as the oxygen-evolving catalyst for solar-driven water splitting due to its more positive potential higher than that for water oxidation. Subsequently $\mathrm{E}_{\mathrm{CB}}$ positions of $\mathrm{Ag}_{3} \mathrm{PO}_{4}$ and $\mathrm{MoS}_{2}$ are determined to be 0.24 and $-0.13 \mathrm{eV}$, respectively. Therefore, the enhanced photocatalytic oxygen-generating performance over the $\mathrm{Ag}_{3} \mathrm{PO}_{4} / \mathrm{MoS}_{2}$ composite photocatalyst could be explained as follows: first, the electrons in the $\mathrm{VB}$ of $\mathrm{Ag}_{3} \mathrm{PO}_{4}$ could be initially excited into $\mathrm{CB}$, and subsequently, may recombine with the holes in the $\mathrm{VB}$ of $\mathrm{MoS}_{2}$ via a possible $\mathrm{Z}$-scheme configuration. Thus, more efficient electron-hole separations and charge transporatation occur in the illuminated hybrid materials due to the existence of highly conductive $\mathrm{MoS}_{2}$ sheets and possible Z-scheme pathway for electron transfer. The electronhole recombination on the surface of $\mathrm{Ag}_{3} \mathrm{PO}_{4}$ can be suppressed, as a result, active holes left on the $\mathrm{VB}$ position of $\mathrm{Ag}_{3} \mathrm{PO}_{4}$

\section{REFERENCES}

Bi, Y. P., Hu, H. Y., Ouyang, S. X., Jiao, Z. B., Lu, G. X., and Ye, J. H. (2012). Selective growth of metallic Ag nanocrystals on $\mathrm{Ag}_{3} \mathrm{PO}_{4}$ submicrocubes for photocatalytic applications. Chem. Eur. J. 18, 14272-14275. doi: $10.1002 /$ chem. 201201435

Botelho, G., Sczancoski, J. C., Andres, J., Gracia, L., and Longo, E. (2015). Experimental and theoretical study on the structure, optical properties, and growth of metallic silver nanostructures in $\mathrm{Ag}_{3} \mathrm{PO}_{4}$. J. Phys. Chem. C 119, 6293-6306. doi: 10.1021/jp512111v may oxidize water into oxygen effectively, leading to highly efficient oxygen evolution performance over the $\mathrm{Ag}_{3} \mathrm{PO}_{4} / \mathrm{MoS}_{2}$ composite photocatalysts.

\section{CONCLUSIONS}

In conclusion, effective $\mathrm{Ag}_{3} \mathrm{PO}_{4} / \mathrm{MoS}_{2}$ composite photocatalysts were successfully fabricated by combining ion-exchange process and electrostatic assembly of $\mathrm{Ag}_{3} \mathrm{PO}_{4}$ nanoparticles on the surface of $\mathrm{MoS}_{2}$ nanosheets. The $\mathrm{Ag}_{3} \mathrm{PO}_{4} / \mathrm{MoS}_{2}$ hybrid materials demonstrated superior interfacial contact and wide-spectrum light-harvesting property in the visible light region. When employed as the catalyst for photocatalytic water splitting, it exhibited highly improved oxygen evolution performance than bulk $\mathrm{Ag}_{3} \mathrm{PO}_{4}$ under LED irradiation. The oxygen-evolving rate of the optimal $\mathrm{Ag}_{3} \mathrm{PO}_{4} / \mathrm{MoS}_{2}$ composite (AM-200) is nearly five times faster than pure $\mathrm{Ag}_{3} \mathrm{PO}_{4}$. The combined characterizations and theoretical analysis on band structures suggest that the enhanced water oxidation efficiency is attributed to remarkable response to visible light, more efficient charge transportation and possibly specific Z-scheme pathway derived from matched band positions. The finding in this work offers a great opportunity in designing and synthesizing novel composite photocatalytic materials for applications in solar energy conversion, allowing us to develop an understanding of the fundamental mechanisms of $\mathrm{Ag}_{3} \mathrm{PO}_{4}$-based composite photocatalytic materials.

\section{AUTHOR CONTRIBUTIONS}

XY and QL: designed the project, guided the study, and polished the manuscript; XC, XX, and LT: conducted the experiments and characterized the samples; HT: revised the manuscript.

\section{ACKNOWLEDGMENTS}

This work was supported by the National Natural Science Foundation of China (51672113), Six Talent Peaks Project in Jiangsu Province (2015-XCL-026), Natural Science Foundation of Jiangsu Province (BK20171299), State Key Laboratory of Photocatalysis on Energy and Environment (SKLPEEKF201705), Fuzhou University, Postgraduate Research \& Practice Innovation Program of Jiangsu Province (SJZZ16_0192), and State Key Laboratory of Advanced Technology for Materials Synthesis and Processing (2016-KF-10), Wuhan University of Technology. 
photoreduction activity under visible light irradiation. Appl. Surf. Sci. 403, 230-239. doi: 10.1016/j.apsusc.2017.01.171

Gyawali, G., and Lee, S. W. (2016). Microwave hydrothermal synthesis and characterization of $\mathrm{Ag}_{3} \mathrm{PO}_{4} / \mathrm{MoS}_{2}$ composite photocatalyst. J. Nanosci. Nanotechnol. 16, 11158-11163. doi: 10.1166/jnn.2016.13471

He, Y., Li, L., Fan, W. G., Zhang, C. X., and Leung, M. K. H. (2018). A novel and facile solvothermal-and-hydrothermal method for synthesis of uniform $\mathrm{BiVO}_{4}$ film with high photoelectrochemical performance. J. Alloys Compd. 732, 593-602. doi: 10.1016/j.jallcom.2017.10.153

Hu, H. Y., Jiao, Z. B., Yu, H. C., Lu, G. X., Ye, J. H., and Bi, Y. P. (2013). Facile synthesis of tetrahedral $\mathrm{Ag}_{3} \mathrm{PO}_{4}$ submicro-crystals with enhanced photocatalytic properties. J. Mater. Chem. A 1, 2387-2390. doi: $10.1039 / \mathrm{c} 2 \mathrm{ta0} 1151 \mathrm{~d}$

Iqbal, S., Pan, Z. W., and Zhou, K. B. (2017). Enhanced photocatalytic hydrogen evolution from in situ formation of few-layered $\mathrm{MoS}_{2} / \mathrm{CdS}$ nanosheet-based van der Waals heterostructures. Nanoscale 9, 6638-6642. doi: 10.1039/C7NR01705G

Koroteev, V. O., Bulusheva, L. G., Asanov, I. P., Shlyakhova, E. V., Vyalikh, D. V., and Okotrub, A. V. (2011). Charge transfer in the $\mathrm{MoS}_{2} /$ Carbon nanotube composite. J. Phys. Chem. C 115, 21199-21204. doi: 10.1021/jp205939e

Kudo, A., and Miseki, Y. (2009). Heterogeneous photocatalyst materials for water splitting. Chem. Soc. Rev. 38, 253-278. doi: 10.1039/B800489G

Li, S. P., Gu, X. Q., Zhao, Y. L., Qiang, Y. H., Zhang, S., and Sui, M. R. (2016). Enhanced visible-light photocatalytic activity and stability by incorporating a small amount of $\mathrm{MoS}_{2}$ into $\mathrm{Ag}_{3} \mathrm{PO}_{4}$ microcrystals. J. Mater. Sci. Mater. Electron. 27, 386-392. doi: 10.1007/s10854-015-3765-x

Lukowski, M. A., Daniel, A. S., Meng, F., Forticaux, A., Li, L. S., and Jin, S. (2013). Enhanced hydrogen evolution catalysis from chemically exfoliated metallic $\mathrm{MoS}_{2}$ nanosheets. J. Am. Chem. Soc. 135, 10274-10277. doi: 10.1021/ja404523s

Lv, J. L., Dai, K., Lu, L. H., Geng, L., Liang, C. H., and Zhu, G. P. (2016). $\mathrm{Cu} / \mathrm{Ag} / \mathrm{Ag}_{3} \mathrm{PO}_{4}$ ternary composite: a hybrid alloy-semiconductor heterojunction structure with visible light photocatalytic properties. J. Alloys Compd. 682, 778-784. doi: 10.1016/j.jallcom.2016.04.313

Maeda, K., and Domen, K. (2010). Photocatalytic water splitting: recent progress and future challenges. J. Phys. Chem. Lett. 1, 2655-2661. doi: 10.1021/jz1007966

Mikkelsen, M., Jorgensen, M., and Krebs, F. C. (2010). The teraton challenge. A review of fixation and transformation of carbon dioxide. Energy Environ. Sci. 3, 43-81. doi: 10.1039/B912904A

Sun, M. X., Wang, Y., Fang, Y. L., Sun, S. F., and Yu, Z. S. (2016). Construction of $\mathrm{MoS}_{2} / \mathrm{CdS} / \mathrm{TiO}_{2}$ ternary composites with enhanced photocatalytic activity and stability. J. Alloys Compd. 684, 335-341. doi: 10.1016/j.jallcom.2016.05.189

Takanabe, K. (2017). Photocatalytic water splitting: quantitative approaches toward photocatalyst by design. ACS Catal. 7, 8006-8022. doi: $10.1021 /$ acscatal.7b02662

Tian, L., Xian, X. Z., Cui, X. K., Tang, H., and Yang, X. F. (2018). Fabrication of modified $\mathrm{g}_{-} \mathrm{C}_{3} \mathrm{~N}_{4}$ nanorod $/ \mathrm{Ag}_{3} \mathrm{PO}_{4}$ nanocomposites for solar-driven photocatalytic oxygen evolution from water splitting. Appl. Surf. Sci. 430, 301-308. doi: 10.1016/j.apsusc.2017.07.185

Wan, J., Du, X., Liu, E. Z., Hu, Y., Fan, J., and Hu, X. Y. (2017). Z-scheme visiblelight-driven $\mathrm{Ag}_{3} \mathrm{PO}_{4}$ nanoparticle@MoS 2 quantum dot/few-layered $\mathrm{MoS}_{2}$ nanosheet heterostructures with high efficiency and stability for photocatalytic selective oxidation. J. Catal. 345, 281-294. doi: 10.1016/j.jcat.2016.11.013

Wang, L., Chai, Y. Y., Ren, J., Ding, J., Liu, Q. Q., and Dai, W. L. (2015). $\mathrm{Ag}_{3} \mathrm{PO}_{4}$ nanoparticles loaded on 3D flower-like spherical $\mathrm{MoS}_{2}$ : a highly efficient hierarchical heterojunction photocatalyst. Dalton Trans. 44, 14625-14634. doi: 10.1039/C5DT01961C

Wang, P. F., Shi, P. H., Hong, Y. C., Zhou, X. J., and Yao, W. F. (2015). Facile deposition of $\mathrm{Ag}_{3} \mathrm{PO}_{4}$ on graphene-like $\mathrm{MoS}_{2}$ nanosheets for highly efficient photocatalysis. Mater. Res. Bull. 62, 24-29. doi: 10.1016/j.materresbull.2014.10.016

Wang, P., Xu, S., Xia, Y., Wang, X., Yu, H., and Yu, J. (2017). Synergistic effect of $\mathrm{CoPi}$-hole and $\mathrm{Cu}$ (II)-electron cocatalysts for enhanced photocatalytic activity and photoinduced stability of $\mathrm{Ag}_{3} \mathrm{PO}_{4}$. Phys. Chem. Chem. Phys. 19, 10309-10316. doi: 10.1039/C7CP01043E

Wang, W., Cheng, B., Yu, J., Liu, G., and Fan, W. (2012). Visible-light photocatalytic activity and deactivation mechanism of $\mathrm{Ag}_{3} \mathrm{PO}_{4}$ spherical particles. Chem. Asian J. 7, 1902-1908. doi: 10.1002/asia.201200197
Wu, Q. F., Bao, S. Y., Tian, B. Z., Xiao, Y. F., and Zhang, J. L. (2016). Doublediffusion-based synthesis of $\mathrm{BiVO}_{4}$ mesoporous single crystals with enhanced photocatalytic activity for oxygen evolution. Chem. Commun. 52, 7478-7481. doi: 10.1039/C6CC02737G

Xiang, Q. J., Yu, J. G., and Jaroniec, M. (2012). Synergetic effect of $\mathrm{MoS}_{2}$ and graphene as cocatalysts for enhanced photocatalytic $\mathrm{H}_{2}$ production activity of $\mathrm{TiO}_{2}$ nanoparticles. J. Am. Chem. Soc. 134, 6575-6578. doi: 10.1021/ja302846n

Xie, G., Zhang, K., Guo, B., Liu, Q., Fang, L., and Gong, J. R. (2013). Graphenebased materials for hydrogen generation from light-driven water splitting. $A d v$. Mater. 25, 3820-3839. doi: 10.1002/adma.201301207

Xin, G., Guo, W., and Ma, T. L. (2009). Effect of annealing temperature on the photocatalytic activity of $\mathrm{WO}_{3}$ for $\mathrm{O}_{2}$ evolution. Appl. Surf. Sci. 256, 165-169. doi: 10.1016/j.apsusc.2009.07.102

Yang, L., Guo, S. H., and Li, X. H. (2017). Au nanoparticles@MoS 2 core-shell structures with moderate $\mathrm{MoS}_{2}$ coverage for efficient photocatalytic water splitting. J. Alloys Compd. 706, 82-88. doi: 10.1016/j.jallcom.2017.02.240

Yang, X. F., Chen, Z. P., Xu, J. S., Tang, H., Chen, K. M., and Jiang, Y. (2015a). Tuning the morphology of $\mathrm{g}^{-} \mathrm{C}_{3} \mathrm{~N}_{4}$ for improvement of $\mathrm{Z}$-scheme photocatalytic water oxidation. ACS Appl. Mater. Interfaces 7, 15285-15293. doi: 10.1021/acsami.5b02649

Yang, X. F., Qin, J. L., Jiang, Y., Chen, K. M., Yan, X. H., Zhang, D., et al. (2015b). Fabrication of $\mathrm{P} 25 / \mathrm{Ag}_{3} \mathrm{PO}_{4} /$ graphene oxide heterostructures for enhanced solar photocatalytic degradation of organic pollutants and bacteria. Appl. Catal. B Environ. 166, 231-240. doi: 10.1016/j.apcatb.2014.11.028

Yang, X., Tang, H., Xu, J., Antonietti, M., and Shalom, M. (2015c). Silver phosphate/graphitic carbon nitride as an efficient photocatalytic tandem system for oxygen evolution. ChemSusChem 8, 1350-1358. doi: 10.1002/cssc.201403168

Yi, Z., Ye, J. , Kikugawa, N., Kako, T., Ouyang, S. X., Stuart-Williams, H., et al. (2010). An orthophosphate semiconductor with photooxidation properties under visible-light irradiation. Nat. Mater. 9, 559-564. doi: 10.1038/nmat2780

Yuan, Y. J., Chen, D. Q., Yang, S. H., Yang, L. X., Wang, J. J., Cao, D. P., et al. (2017). Constructing noble-metal-free Z-scheme photocatalytic overall water splitting systems using $\mathrm{MoS}_{2}$ nanosheet modified $\mathrm{CdS}$ as a $\mathrm{H}_{2}$ evolution photocatalyst. J. Mater. Chem. A 5, 21205-21213. doi: 10.1039/C7TA06644A

Zeng, Q. Y., Li, J. H., Li, L. S., Bai, J., Xia, L. G., and Zhou, B. X. (2017). Synthesis of $\mathrm{WO}_{3} / \mathrm{BiVO}_{4}$ photoanode using a reaction of bismuth nitrate with peroxovanadate on $\mathrm{WO}_{3}$ film for efficient photoelectrocatalytic water splitting and organic pollutant degradation. Appl. Catal. B Environ. 217, 21-29. doi: 10.1016/j.apcatb.2017.05.072

Zhang, J., Huang, L. H., Lu, Z. D., Jin, Z. L., Wang, X. Y., Xu, G. L., et al. (2016). Crystal face regulating $\mathrm{MoS}_{2} / \mathrm{TiO}_{2}(001)$ heterostructure for high photocatalytic activity. J. Alloys Compd. 688, 840-848. doi: 10.1016/j.jallcom.2016.07.263

Zheng, Y., Zhang, W. Q., Li, Y. F., Chen, J., Yu, B., Wang, J. C., et al. (2017). Energy related $\mathrm{CO}_{2}$ conversion and utilization: advanced materials/nanomaterials, reaction mechanisms and technologies. Nano Energy 40, 512-539. doi: 10.1016/j.nanoen.2017.08.049

Zhou, T. H., Zhang, G. Z., Ma, P. J., Qiu, X. L., Zhang, H. W., Yang, H., et al. (2018). Efficient degradation of rhodamine $B$ with magnetically separable $\mathrm{Ag}_{3} \mathrm{PO}_{4} @ \mathrm{MgFe}_{2} \mathrm{O}_{4}$ composites under visible irradiation. J. Alloys Compd. 735, 1277-1290. doi: 10.1016/j.jallcom.2017.11.245

Zhu, C. S., Zhang, L., Jiang, B., Zheng, J. T., Hu, P., Li, S. J., et al. (2016). Fabrication of Z-scheme $\mathrm{Ag}_{3} \mathrm{PO}_{4} / \mathrm{MoS}_{2}$ composites with enhanced photocatalytic activity and stability for organic pollutant degradation. Appl. Surf. Sci. 377, 99-108. doi: 10.1016/j.apsusc.2016.03.143

Conflict of Interest Statement: The authors declare that the research was conducted in the absence of any commercial or financial relationships that could be construed as a potential conflict of interest.

Copyright () 2018 Cui, Yang, Xian, Tian, Tang and Liu. This is an open-access article distributed under the terms of the Creative Commons Attribution License (CC $B Y)$. The use, distribution or reproduction in other forums is permitted, provided the original author(s) and the copyright owner are credited and that the original publication in this journal is cited, in accordance with accepted academic practice. No use, distribution or reproduction is permitted which does not comply with these terms. 